\title{
Exploring the relative lack of impact of research on 'ability grouping' in England: a discourse analytic account
}

Professor Becky Francis, Professor Louise Archer, Professor Jeremy Hodgen*, Dr David Pepper, Dr Becky Taylor; Dr Mary-Claire Travers (King's College London; *University of Nottingham).

Corresponding author:

Professor Becky Francis

Department of Education and Professional Studies, Waterloo Bridge Wing, Franklin-Wilkins Building Waterloo Road London SE1 9NH Becky.Francis@kcl.ac.uk 
Exploring the relative lack of impact of research on 'ability grouping' in England: a discourse analytic account

\begin{abstract}
Grouping students by 'ability' is a topic of long-standing contention in English education policy, research and practice. While policymakers have frequently advocated the practice as reflecting educational 'standards', research has consistently failed to find significant benefits of 'ability' grouping; and indeed has identified disadvantages for some (low attaining) pupil groups. However, this research evidence has apparently failed to impact practice in England. This article, contextualised by the authors' interests in education and social inequality, seeks to do two things. Firstly, it provides a brief analysis of the existing research evidence on the impact of 'ability' grouping, with particular reference to socioeconomic inequality; identifying seven different explanations for the poorer progress of pupils in low sets that emerge from the literature. Secondly, it applies Foucaultian 'analysis of discourse' to propose potential explanations for the apparent lack of traction of existing research with policy and practice, arguing that practices of 'ability grouping' reflect cultural investments in discourses of 'natural order' and hierarchy, with particular resonance for the discursive and political habitus of middle class parents. We postulate that investing in a powerful counter-discourse of enlightenment science, illustrated via our current randomised control trial of different approaches to pupil grouping, may offer a means to challenge hegemonic discourses that underpin current classroom practice.
\end{abstract}

Key words: ability grouping, setting, streaming, mixed ability grouping, social class, discourse, impact 


\section{Exploring the relative lack of impact of research on 'ability grouping' in England: a discourse analytic account}

\section{Background}

Educational attainment in England is highly stratified by social class. There is an especially strong relationship between family wealth and educational outcomes, and between family wealth and posteducation occupational outcomes (Jerrim \& Macmillan, 2014). And there is a close correlation between socio-economic background and educational attainment, with those from the lowest socio-economic backgrounds achieving least, and those from the highest socio-economic backgrounds attaining the highest educational outcomes (Clifton \& Cook, 2012). The significance of this issue for equality of opportunity, social justice, and social mobility, has motivated Government attention to the socioeconomic gap for educational attainment (see, e.g. Francis \& Wong, 2013). Yet explanations for this level of social differentiation have been harder to establish. Research has pointed to the impact of wealth inequality, and to the impact of socio-economic background on 'school readiness' means that children from low socio-economic backgrounds tend to be significantly 'behind' their middleclass counterparts even when starting school (Wagdofel \& Washbrook, 2010). This points to the strong impact of social factors external to education in reproducing educational inequality (Whitty \& Anders, 2014; Lupton, 2015). However, socio-economic attainment gaps widen, rather than narrow, as children progress through school (Clifton \& Cook, 2012), suggesting that schooling exacerbates, rather than mitigates, inequalities in attainment outcomes. Meanwhile, the evidence that schools can make a positive difference is provided by the many schools that facilitate high achievement for their disadvantaged pupils (Hutchings et al, 2014).

So what school-level factors explain these trends? Although school quality and between-school social segregation is an important issue (see e.g. Francis \& Wong, 2013), within-school segregation has been shown to be an even stronger factor: attainment of disadvantaged pupils tends to remain an issue within individual schools, including those schools that are high achieving and/or rated as good quality by Ofsted (Wiliam \& Bartholomew, 2004; Cook, 2012; 2013; Strand, 2014). Indeed, the UK system has smaller quality variances between than within schools (Ainscow et al, 2012; Shleicher, 2012). This relates to teacher quality and allocation (Husbands, 2012), but also (and connectedly) to the impact of within school segregation - a key form of which is 'ability grouping'. It is important to note here that the authors do not subscribe to conceptions of 'ability' as ascribed and fixed: rather we see it as malleable, and prior 
attainment to reflect a range of societal factors that impact educational progress and outcome. Hence our use of inverted commas.

This has three parts. In the first it provides a brief analysis of the existing research evidence on the impact of 'ability' grouping, with particular reference to socio-economic inequality. Using thematic content analysis, we identify seven different explanations for the poorer progress of pupils in low sets that emerge from the literature. In the second, a Foucaultian 'analysis of discourse' approach (Foucault, 1980; Parker, 1990), is then applied to recent policy debates, to propose potential explanations for the apparent lack of traction of existing research with policy and practice. In the third, we draw on these reflections and their implications to discuss the potential of mobilising discourses which might better disrupt existing, historically hegemonic discourses on 'ability grouping', and set out the case of our present empirical study on student grouping as a potential exemplar of this approach.

The term 'ability grouping' obfuscates several issues. Firstly, it confuses educational attainment with a notion of innate potential academic 'ability'. This conflation of current attainment as a proxy of innate potential speaks to a pervasive UK tradition of perceiving educational inequalities in outcome as 'natural' and even inevitable. Secondly, as Dracup (2014) observes, the term 'ability grouping' can include (and is used to allude to) a very diverse range of discrete practices. Arguably the term is so unhelpful that it should be discarded; and indeed in our present research project (outlined below) we refer instead to 'attainment grouping'. However, the term 'ability grouping' is hegemonic across the literature, and (as noted with concern by Dracup, 2014) researchers commonly uses this term rather than explaining the specific discrete practices examined by the research. These practices most frequently include streaming and banding, setting, and within-class grouping by attainment. 'Streaming', referred to in the US as 'tracking', involves separating pupils according to academic 'ability' across all (or a majority of) subjects, so that pupils remain in the same group for all or most lessons. 'Banding' is similar: several classes are grouped together in a band, and within the band setting may also occur. Typically there may be high, middle and low bands each including several classes. Setting is premised on the same notion of academic ability, but is more flexible and can involve smaller groups, with pupils being put into different attainment sets for different subject areas. Within-class segregation by attainment tends to be used in primary schools, wherein 'ability tables' (whereby children are seated at different tables depending on their proficiency) are used with increasing frequency for key curriculum areas even from Key Stage 1 (Hallam et al, 2003). Indeed the practice of streaming is becoming more prevalent in primary schools (Hallam et al, 2013). 
These practices - especially that of setting - have become dominant in English schooling. The precise extent of setting and streaming in the English system is far from clear; especially with regard to quantifying these discrete approaches. Nevertheless figures suggest that these practices - present in many schools even at the height of comprehensivisation - have steadily increased, and now predominate. Figures cited by Dracup (2014), provided in response to a Parliamentary Question in 2011, suggest that almost three quarters of secondary pupils are taught in sets or streams for maths (71\%); nearly two-thirds for Science (62\%); and over half for English (58\%). Other sources suggest the figures are even higher (HMSO, 2005); and it is likely that if the focus was limited to Key Stage 4 (the preparation for GCSE exams at the end of compulsory schooling), the proportions would be higher still.

As we shall see, these practices have promoted social segregation (Ball, 1981; Cassen \& Kingdon, 2007; OECD, 2014), with working class pupils - and those from some minority ethnic groups - disproportionately represented in low sets and streams (Kutnick et al, 2005; Dunne et al, 2007; Cassen \& Kingdon, 2007). Although this trend might be predicted given the impact of social inequality on 'school readiness' noted above (meaning that children from low SES backgrounds tend to start from a lower base), over the past half-century practices of allocation have been consistently shown to be biased (Jackson, 1964; Tomlinson, 1987; Dunne et al 2007), and not necessarily reflective of 'ability' or prior attainment (Jackson, 1964; Dunne et al, 2007).

There is an extensive research literature on the impact of 'ability grouping' on pupil outcomes, as elaborated in the EEF/Sutton Trust Toolkit (2014), and in several other reviews (see e.g. Slavin, 1990; Ireson and Hallam, 2001; Kutnick et al, 2005). The evidence suggests that overall these practices are not of significant benefit to attainment, with a negative impact for lower sets and streams - those wherein pupils from lower socio-economic groups are over-representedii. As Slavin (1990) observes, advocates of 'ability grouping' maintain it allows teachers to adapt instruction to the needs of a diverse student body, giving them the opportunity to provide more difficult material to high achievers, and more support to low achievers. Yet Slavin's (1990) systematic review of the most significant, methodologically-robust research from the US and elsewhere found that the effects of ability grouping on achievement are statistically insignificant (see also Nomi, 2010). Ireson et al [2005] more recently investigated the effect of setting in English, Maths and Science at GCSE, and found no significant effects for setting in either subject. This overall finding could be read as suggesting that ability grouping neither helps nor hinders, but as we shall see, there is a negative impact for those in lower sets, a majority of whom are from low socio-economic backgrounds. As Boaler \& Wiliam (2001) summarise,

"...bringing together the different research studies on ability grouping the general conclusion is that streaming has no academic benefits whatsoever, while setting confers small academic benefits on 
some high-attaining students, at the expense of large disadvantages for lower attainers". (p. 179; see also EEF, 2014).

\section{Potential explanations for poor outcomes among those in low sets and streams}

There have been various explanations identified for the negative impact of being placed in a low stream or set. Slavin (1990) lists potential factors as including low groups being subject to "a slower pace and lower quality of instruction, have teachers who are less experienced or able and who do not want to teach low-track classes, face low expectations of performance and have few behavioural models" (Slavin, 1990; 473). Our review of the literature on setting and streaming involved thematic content analysis to inductively identify and analyse the various explanations alluded to in different studies as potentially explaining the poorer progress and outcomes for pupils in low 'ability groups'. The analysis included identification of these various explanations emerging in different studies, and their categorisation (Fereday \& Muir-Cochrane, 2006). Via this process, we have identified seven key problems identified in the research. These are:

$>$ misallocation to groups

$>$ lack of fluidity of groups

$>$ quality of teaching for different groups

$>$ teacher expectations of pupils

$>$ pedagogy, curriculum and assessment applied to different groups

$>$ pupil perception and experiences of 'ability' grouping, and impact on their learner identities

$>$ These different factors working together to cause a self-fulfilling prophecy.

These various explanations are now discussed in turn.

\section{Misallocation to groups}

There is extensive evidence that certain groups of children (those from lower socio-economic groups, and from particular minority ethnic groups) are over-represented in low sets and streams, and that such allocation does not always match 'ability' as designated by IQ tests (Jackson, 1964) or test scores (Dunne et al, 2007). In fact while Dunne et al (2007) found prior attainment was the main predictor of set placement, they found it a relatively poor predictor, with for example over half the pupils with low prior attainment in English being placed in middle or high sets. They also found that social class is a significant predictor of set placement, with those pupils from higher socio-economic status (SES) backgrounds being more likely to be assigned to higher sets, and less likely to be assigned to lower sets. They conclude that "Although prior attainment remains statistically significant, setting decisions are clearly not made on this 
basis alone" (2007, p. xii). However, teachers and schools tend to underestimate the extent of pupil misallocation (Hallam \& Ireson, 2005). Allocation to groups, arbitrary or otherwise, has been shown to impact on subsequent outcomes (Linchevski \& Kutscher, 1998; Ireson et al, 2005).

\section{Lack of fluidity of groups}

Once placed in an 'ability group' pupils tend to remain there, irrespective of their progress or attainment (Flores, 1999; Dunne et al, 2007; Dunne et al, 2010). Teachers and schools tend to overestimate the extent of movement between groups (Hallam and Ireson, 2005).

\section{Quality of teaching for different groups}

There is some evidence that teachers perceived as lower quality tend to be placed with lower ability groups (Slavin, 1990; Hallam et al, 2001). Higher sets are more likely to be allocated highly qualified and experienced teachers, whereas lower sets are less likely to be taught by a subject specialist, and experience more changes of teacher (Kutnick et al, 2005).

\section{Teacher expectations and related pedagogy}

Teachers think about, and respond differently towards, pupils according to perceptions of their 'ability' (e.g. Jackson 1964; Croll and Moses 1985; Hacker et al 1991; Suknandan and Lee, 1998). Teacher expectations also have a bearing on practice, with Ireson et al (2005) and Boaler et al (2000) showing that teachers of high sets convey high expectations through provision of fast-paced and challenging work, whereas pupils in low sets receive slow-paced teaching that covers less of the curriculum. Research also shows that pupils in higher sets are given more homework (Ireson \& Hallam, 2001). Boaler et al (2000) found teachers catered effectively to mixed ability groups in Year 8, using a variety of strategies for differentiation but adopted much more limited teaching styles when teaching setted groups (see also Hallam \& Ireson, 2005) - and Boaler reports these styles were associated with disaffection amongst students.

Impoverished curriculum and qualifications:

Setting can also produce an 'artificial ceiling', wherein pupils in lower sets are excluded from higher tier study and qualification routes (Dunne et al, 2007; Ireson et al, 2005). This compounds the 'lack of fluidity' problem because students who 'move up' a set have difficulty catching up with the work (Macqueen, 2012).

\section{Pupil perception and experiences of 'ability' grouping, and impact on their learner identities}


The impact of 'ability' grouping on student identities and expectations is also thought to impact on outcomes (Kutnick et al, 2005; EEF 2014). Some early sociological work in education attended to the impact of streaming on students' social and educational identities and consequent educational engagement. Ball (1981) observed that attainment grouping created polarization of students into pro- and anti-school factions. Those in low attainment groups became anti-school, with consequent detrimental impact on their achievement and aspirations. In this sense, placement in low streams/sets is suggested to label students and provoke self-fulfilling prophecies by a) damaging children's self-perception of ability and reducing their confidence (and stigmatising them); and b) by consequent disassociation with education and investment in alternative forms of status. Such findings, therefore, suggest a further potential explanation for the underachievement of pupils in low sets. Certainly, recent research by Hallam \& Ireson (2007) hints at continuing dissatisfaction among students in low sets, finding that nearly twothirds (62\%) of young people in bottom sets expressed a wish to change set.

\section{Self-fulfilling prophecy}

The combination of these factors, particularly teacher quality, misallocation, lack of fluidity and impoverished curriculum, restrict lower group pupils' access to the full curriculum, which in turn creates barriers to moving 'up' sets and to higher tier study (Jackson, 1964). Hence in this way and others, the various factors may work together to create and perpetuate a self-fulfilling prophecy concerning outcomes for different pupils.

The evidence about the impact of placement in a low 'ability' groups on (poorer) educational progress and outcomes, coupled with the findings about the disproportionate representation of economicallydisadvantaged pupils in these low sets, provide a clear hypothesis that these practices may contribute to the socio-economic attainment gap in the UK education system. Preoccupation with this gap has been a feature of the current and previous Government administrations, which have developed a range of educational policies to address it (e.g. City Academies, the Pupil Premium, and so on). Despite all this, the existing research findings on 'ability' grouping have had little traction in impacting education policy and/or teaching practice, where practices of setting, and advocacy for itiii, remain prevalent. Indeed, these practices have extended hegemony in schools in recent decades, following their active promotion by Government and its agencies (HMSO, 2005). As the TES (2013) surmises, "The practice of grouping classes by ability has long had strong backing from the top" (p.1). Setting was notably advocated by the incoming New Labour administration in 1997 as an aspect of its focus on 'education, education, education' (HMSO, 2005). Ofsted has regularly promoted the practice (see Dracup, 2014). And most recently, in Autumn 2014, No.10 plans to announce that all secondary schools should be forced to adopt setting were leaked 
(Wintour, 2014). This was speedily retracted following a social media storm and denials from the DfE (see Dracup, 2014); but nevertheless it was suggested by No. 10 that the initiative might form a pledge in the imminent Conservative manifesto.

What is notable is the disconnect between this strong advocacy for setting, and research evidence. So what might explain the current dissonance between research and practice?

\section{Possible explanations for the lack of research impact on practice}

Theoretical lens and analytic approach

We approach this question drawing on a Foucaultian 'analysis of discourse' approach (Parker, 1990; Parker \& Burman, 1993), interwoven with recognition as to how discourses may be articulated and wielded by policymakers, journalists and other individuals as policy rhetorics (Edwards and Nicholl, 2006; Edwards et al 2004; Francis, 2015) ${ }^{\text {iv }}$. From a Foucaultian perspective, discourses are not 'right or wrong', but produce 'regimes of truth' which elevate and naturalise particular productions of the world. From this perspective, the analyst's intention is to explore the productive nature of different discursive narratives; specifically their power in producing subjects and objects in particular ways (Foucault, 1980). Like Nicholl and Edwards (2004), our attention is also to the ways in which particular discourses and rhetorical strategies are mobilised by policymakers, and other subjects, to articulate particular representations of the world that position subjects and objects in relations of power. Drawing on these perspectives, it becomes possible to identify the ways in which the practice of 'ability' grouping is both produced within, and acts as a signifier for, particular discourses.

We have applied this analytical lens to recent policy debates and texts which attend to 'ability grouping', including an especial focus on the education White Papers of the New Labour Government (the predecessor Government at the time of analsysis) (DfES, 1997; DCSF, 2005), and interventions by members of the Coalition Government which build on this policy status quo. These texts were analysed by Author 1, and her analysis of discourses emerging was assessed against the original texts by Author 2 .

\section{The discourse of 'natural order'}

We suggest that it is the hegemonic power of a 'discursive bundle' (Ball, 2013) which constructs segregation by 'ability' as indicative of 'standards', 'rigour', and a 'natural order', that primarily explains the lack of traction of the body of research on 'ability' grouping. 
Within the semiotics of policy discourse, setting has somehow become a signifier for 'academic high standards'. The incoming New Labour Government's first White Paper 'Excellence in Schools' was focused squarely on raising educational 'standards', notoriously using this word 173 times. Setting was notably advocated within the paper as an aspect of this agenda, including the following statement:

Setting, particularly in science, maths and languages, is proving effective in many schools. We do not believe that any single model of grouping pupils should be imposed on secondary schools, but unless a school can demonstrate that it is getting better than expected results through a different approach, we do make the presumption that setting should be the norm in secondary schools. (HMSO, 1997, p. 38).

As the then Government explained in its 2005 White Paper 'Higher Standards, Better Schools for All',

Grouping students can help to build motivation, social skills and independence; and most importantly can raise standards because pupils are better engaged in their own learning. We have encouraged schools to use setting since 1997. (HMSO, 2005, p. 58, our emphasis).

In reference to comprehensives, the White Paper bemoans that,

[...] their introduction was often accompanied by all-ability classes, which made setting by subject ability too rare. Many retained their old secondary modern intake, and failed to improve. There were simply not enough pressures in the system to raise standards. (p. 5, our emphasis).

Likewise, in his 2007 Green Paper, the then Opposition Minister for Education Michael Gove again linked setting to 'standards', pledging that he would "alter guidance to Ofsted to ensure that schools particularly those not performing at high levels - set all academic subjects by ability" (TES, 2013). As observed by the TES (2013), the Green Paper was endorsed by David Cameron, who has declared himself to be "passionate about the importance of setting by ability" (a position he has recently reiterated; see Savage, 2015), and once pledged to introduce "a 'grammar stream' in every subject in every school". Ofsted itself has regularly promoted the practice (see Dracup, 2014), again as expressive of 'high standards"v. Dracup (2014) quotes media coverage in 1999 of an Ofsted intervention as follows: "Setting, rather than streaming, in primary schools provides a powerful lever for raising standards [...], say Her Majesty's Inspectors from OFSTED."

As we have seen, this association between setting and standards cannot have been derived from the research evidence. Indeed, a review specifically commissioned by the DCSF under New Labour reiterated the lack of any overall positive effect from setting (Kutnick et al, 2005). (Dracup [2014] maintains that this 
did secure a somewhat more tentative approach to the topic from the [then] DCSF). What is also notable is that in the 1997 White Papers quoted above strong claims are made which use the language of evidence ("proving effective", "demonstrate", and so on), without any reference to supporting evidence bar reference to a single case study school. The following is illustrative:

Mixed ability teaching has proved successful only in the hands of the best teachers and should be used only where it is appropriate and can be seen to be effective. We make a presumption that setting should be the norm in secondary schools. We will explore effective new approaches to teaching and learning and spread them across schools. (HMSO, 1997, p.37, our emphasis).

Perhaps this is reflective of confidence that these claims represent a common-sense, 'uncontestable' view: in other words, setting practices are part of a discursive production of intelligibility in the education system. This may also explain the close association between 'standards', and assumptions of a need to segregate pupils in a hierarchy of 'ability'.

As the then Government explained,

'Mixed ability grouping... requires excellent teaching and in some schools has worked well. But in too many cases it has failed both to stretch the brightest and to respond to the needs of those who have fallen behind. (HMSO, 1997, p. 38).

Setting is again here produced as generally more effective than 'mixed ability' grouping, and the explanation for this elevation is that mixed attainment practice is not meeting the different needs of all pupils and especially not to 'stretch the brightest' (a common trope in this narrative). As Michael Gove concurred, setting is "the only solution" that enables all students "to learn in accordance with their particular aptitude and ability" (2007, cited in TES, 2013).

We suggest that the discursive production of hierarchies of 'ability', and segregation, as expressive of educational 'standards' is a manifestation of various longstanding narratives in English culture (White, 2005; see also Stobart, 2008).

Extensive genealogy of this interpolation of the practice of segregation as indicative of educational 'standards' and academic rigor is beyond the scope of this article. However, English education arguably remains highly influenced by its past ${ }^{\mathrm{vi}}$. This can be illustrated by the resonance of nostalgic imagery of public schooling which still characterises many expressions of popular culture (from Harry Potter to St Trinians), and which remains significant of 'Britishness' overseas (see e.g. depictions in movies such as Three Men and a Little Lady). The private school sector appears highly attuned to the appeal of such 
nostalgic imagery and the notions of distinction on which they are premised, in these institutions' maintenance of uniforms that would not be out of place in the 1930s (shorts, piping, caps and boaters, and so on), and their appropriation of stately homes for school buildings. Such nostalgic investments also apply to the continuing popularity of grammar schools in many quarters (still highly popular within the Conservative party, and their re-instigation a key element of the UK Independence Party 2015 manifesto). Both the prior tripartite system ${ }^{\text {vii }}$ and the independent schools sector have prioritised segregation (by wealth, 'ability', or both). Under the tripartite system children were segregated into grammars or secondary moderns via testing at the age of 11 ; and the majority of private schools continue practice attainment-based entry (via their own test assessments, which families must pay to take), in addition to charging fees. Hence this quintessentially 'English' imagery, and the (classed) segregation it projects as 'natural', speaks to long-standing cultural phantasies of identity, aspiration and 'natural order'.

This investment in hierarchy and segregation may partly explain a documented trend for middle-class parents especially to favour 'ability grouping' (Ball et al, 1994; Kohn, 1998). Prime Minister David Cameron appears attuned to this preference, saying in 2006, "I want no child held back, so my priority is not selection by ability between schools but setting by ability within schools, because every parent knows that a high quality education means engaging children at the right level." (Cited in Dracup, 2014). It appears that this discourse of a 'natural order' needs no external evidence to support it; rather, it is one that 'intelligiblises' our social world (Butler, 1993), and brings into being 'naturally' unequal subjects. The power of this discourse renders counter-claims (and even evidence) as unnatural.

This discourse of 'natural order', and the related practice of segregation, also speaks to other sociallyclassed narratives that interpolate, and are wielded by, middle-class parents. For example, although not exclusive to middle class parents, it has been extensively documented how a competitive, 'entitled' mindset frequently characterises middle class parents' engagements with their children's school (Reay, 1998; Reay et al, 2011; Kohn, 1998). These parents expect and demand 'the best' for their children, frequently mobilising financial and cultural resources to secure advantage. Research has depicted the competitive and individualistic, aspirational contemporary 'habitus' for many middle class parents, and how these discursive phantasies and practices are especially exacerbated in the context of education (Crozier et al, 2011; Vincent \& Ball, 2006; 2007). Demand for setting and other forms of 'ability grouping' forms part of these constructions (Kohn, 1998; Oakes \& Guiton, 1995), reflecting assumptions among middle-class parents that their children are/will be high achieving (and so will populate top sets and/or streams) (Reay et al, 2011; Ball et al, 1994).

Such trends of active parental engagement with the 'project' of securing the best quality education for their children are also well-evidenced in the research literature on school engagement (and the nature of 
this engagement) depending on socio-economic background (e.g. Vincent \& Ball, 2006; Crozier \& Reay, 2011; Francis \& Hutchings, 2013). These documented practices illustrate how the discourse of 'natural

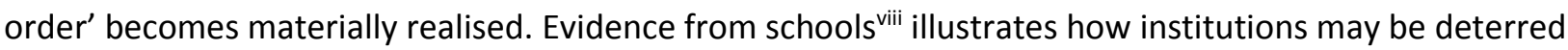
from pursuing mixed-attainment grouping by perceptions of middle-class parental preferences (real or imagined), given that many schools are keen to retain and attract middle-class families. Research has also shown how middle-class parents can be effective in mobilising their social capital to campaign for the school to meet the perceived needs of their offspring (Crozier et al, 2011; Vincent \& Ball, Reay et al, 2011); including for them to be in high attainment groups (Kohn, 1998). ix

The literature on different forms of pupil grouping, and the lack of overall positive effect of setting, speaks then against this formidable discursive hegemony, in which setting and other 'ability' grouping practices are signifiers within discourses of standards and 'natural' distinction that constitute technologies of privilege. These discourses are central to the re/production of privilege, and to its defence. Production of this intelligible, 'natural' order means that these narratives appeal especially directly to the desires and phantasies of the middle class parents interpolated as aspirational, active consumers of education. Against such powerful discursive productions of the 'obvious', 'real', and 'natural', the research evidence on the impact on setting sits blasphemously as a discomfiting, 'impossible' aside, and may be deliberately undermined, or simply ignored. In order to disrupt such positionings, the literature would need to mobilise equally powerful discourses. These counter-narratives would need to be especially forceful, given the appeal of the 'pro-segregation' discourse to middle class desire.

\section{Reasonable evidence?}

A potential source for this necessary discursive power would be the empiricist appeal to 'reason' and science, via which to present convincing empirical findings. This is not to suggest that the 'natural order' discourse recognises/is amenable to reason; but rather that a discourse of 'scientific reason' might have the necessary traction to constitute a (potentially hegemonic) alternative to that of 'natural order'. Many key poststructuralist authors have noted the power of enlightenment, 'scientific' discourse in Western contexts (e.g. see e.g. Feyerabend, 1975; Lyotard, 1984), their influence and resonance in European culture since the Renaissance, and the association between 'reason' and other signifiers of power which work to Other alternative narratives. Indeed, such enlightenment discourses have often been presented as potentially violent and detrimental for precisely these reasons (see e.g. Harding, 1980; 1982). Albeit other authors have also observed how human rights proponents and other 'emancipatory' movements have mobilised enlightenment narratives of reason and science to argue for greater equality (Balbus, 1986). 
Academic research - especially empirical research - clearly articulates these discourses of 'scientific reason' both in its articulation and evaluation. Positivist research does this most overtly and selfconsciously, and research methods associated with positivism act especially effectively as signifiers of this discourse. In this way, one might expect that academic research, significant of this powerful enlightenment discourse, might have the potential to disrupt and/or usurp the discourse of 'natural order'. Powerful discursive practices currently operating in academia and government around 'evidencebased practice' also suggest a fertile terrain for the potential traction of discourses of 'scientific reason'.

However, in the case of empirical research findings on the impact of 'ability grouping', discursive traction may be impeded by several limitations with the research base that render the emergent discursive narrative vulnerable to disregard. Firstly, the studies underpinning such conclusions are often dated (and occasionally results are contradictory, see e.g. Collins \& Gan, 2013). Albeit some key researchers have done an admirable job in pursuing continuous research on setting and streaming from a variety of angles in the English case: the work of Sue Hallam and colleagues is especially noteworthy here (see reference list). Secondly, the research is less clear in relation to high achieving students, wherein some studies have suggested that students designated 'Gifted' benefit from being addressed separately (see Dracup, 2014). Emphasis on meeting the needs of these high attaining students has been promoted in England in recent years via a range of initiatives such as New Labour's 'Gifted \& Talented' programme, and Ofsted accountability (Warwick, 2013). Advocacy for segregation on the basis of (high) attainment contradicts the messages of a lack of benefit in segregation emerging from the research literature on setting and streaming; and perhaps therefore potentially undermines them.

It may also be that the potential consequence of the relative lack of attention to low-attaining groups for inequality of outcomes is not understood due to a lack of attention to socio-economic inequalities within the evidence base. Relatively few studies have focused on the issue of 'ability' grouping with direct attention to the issue of social class (for a notable exceptions, see Jackson, 1968). Finally, and importantly in relation to the issue of research impact, the different potential explanations for the negative impact of setting and steaming on those in low attainment groups are not disaggregated, and/or established as causal, in the research (which has predominantly focused on patterns of outcome). As a result, there is much that we still do not know about the relative impact of the seven different elements outlined earlier in this article potentially impacting the outcomes for pupils in different sets and streams. That the majority of studies do not disaggregate factors which may impact outcomes for students, renders it difficult to deduce whether detrimental outcomes are due to the practice of grouping by 'ability' per se (due to self-fulfilling prophecies precipitated by the act of placement in a low attaining group), or whether 
they might be simply due to poor practices associated with it (and which better practice might therefore mitigate or even reverse).

This body of evidence will therefore likely prove inadequate to disrupt existing practices of long-standing that are very widely established across the English schooling system, and which retain a powerful symbolic hegemony in their relation to discourses of standards, natural order, and aspiration. As noted, policymaker proponents of setting frequently rhetorically position their own views as 'rational', and even evidenced. Any research evidence embedded in a discourse of 'scientific reason' would need then to be especially incontrovertible to counter the (unevidenced) narrative that setting is 'proven effective'.

Our present project, funded by the Education Endowment Foundation, seeks to redress some of the identified challenges; especially that of the lack of disaggregation of explanatory factors in the literature. But also, the project's experimental design reflects powerful (positivist) enlightenment discourses of 'science' and the search for 'truth', which we hope may support the discursive traction of our findings. Specifically, it adopts a randomised control trial (RCT) design. There has been recognition (and frustration) within the research community at the promulgation of RCTs as the 'gold standard' in research design by some researchers and policymakers (Hammersley, 2008; Christmas, 2014), and at the level of trust (sometimes misplaced) in RCTs displayed by the policy community. We do not personally subscribe to these views: we see RCTs as one valid methodological approach among many, and as especially useful for specific research purposes. Indeed, our research design includes a mixed methods approach (interviews and surveys, alongside the interventions and pre and post tests), which is already proving vital for explanatory purposes - and the discourse analytic approach explicated above is being applied to qualitative data . However, in addition to simple design efficacy (given we wish to identity effective practice), our intention is to utilise the symbolic power of RCTs to support research impact. In other words, we see the potential of RCT design as a rhetorical tool (Edwards \& Nicholl, 2006). We are not so naive as to think that even the application of modes of evidence-gathering which symbolise 'hard science' necessarily precipitate evidence-informed policy making. However, we do hope that the approach lends sufficient discursive power to better enable being heard. In this sense, we intend to use our RCT project to extend investigation of individual and collective agency in rhetorical and discursive deployment (and its impact), elaborated in Francis (2015).

The project involves the randomised control trialling of two different 'treatments' (interventions) that draw on existing research evidence to implement 'good practice interventions' in two different approaches to pupil grouping. One trial explores the impact of good practice in mixed attainment teaching and grouping: our review of the literature found that the constitution of good practice in mixed 
attainment classes is currently an under-researched area. The other explores the impact of removing or mitigating several of the various detrimental elements associated with setting, identified above. In this way, and given the use of a control group, the trial can explore whether the poorer outcomes for students in low sets recorded in the existing literature are due to the act of segregation by 'ability' per se, or to poor practices associated with it. The project will monitor and compare progress and attainment outcomes for low achieving and other pupils following the adoption of different approaches to pupil grouping. In this way, it is intended to provide evidence concerning the efficacy of different approaches to pupil grouping on improving the attainment of (disproportionately disadvantaged) low achieving pupils, and hence for narrowing the socio-economic gap for attainment ${ }^{x}$.

\section{Conclusion}

We have summarised the existing research evidence and debate around 'ability' grouping, and conclusions of an overall lack of significance of grouping by ability, attending especially to the findings of poorer progress for lower attainment groups, and the implications for social inequality given the overrepresentation of students from disadvantaged backgrounds in these groups. Based on our analysis of the existing literature we have identified seven different potential explanations for the poorer progress of young people in low attaining groups. We also observe that these various findings tend not to be disaggregated or established as causal in the literature; revealing a key gap that needs to be addressed by research.

Given the strong agreement in the (extensive) research literature, we considered why these research findings appear to have had little impact on policy and practice in the English case - wherein setting continues to predominate in practice, and to be actively promoted by policymakers in spite of the research evidence. We have argued that this can be explained by the interpolation of segregational practices as symbolic of academic 'standards' and hierarchies that appeal both to longstanding phantasies of natural order, and to contemporary middle class desire and habitus. Hence discursive practices and policy narratives reflect and (re)produce historic, naturalised assumptions of distinction, fixed/essential 'ability', and the benefits of social segregation. Our analysis of Government policy rhetoric on setting illustrates the way in which the production of hierarchies of ability via a discourse of 'natural order' acts as a technology of privilege, and renders alternative accounts (including research evidence) as unintelligible. 
This analysis has clear implications for notions of 'evidence-based policy', which tends to neglect how evidence can be negated, dismissed, or rendered 'impossible' within particular discursive orthodoxies. Discourse analytic perspectives would suggest that the only way to counter such powerful discourses is via mobilisation of alternative narratives with a similar discursive power. We have suggested that enlightenment discourses of 'scientific truth' - with RCTs and experimental methods as a key signifier within this narrative - offer potential here, for potential discursive traction and contestation of currently hegemonic narratives that produce 'ability' grouping as natural and desirable. To this end, we briefly outlined our research design for the Education Endowment Foundation-funded project 'Best Practice in Grouping Students'. We hope that the project will make an important contribution to the existing literature on different approaches to grouping students. But also, given its use of an experimental, largescale RCT design, we hope it might have the requisite symbolic power for its findings to destabilise existing hegemonic narratives in the field, potentially impacting policy and practice.Clearly, given the continued inequitable practices and socially-segregationist patterns currently perpetuated by 'ability grouping', the traction of research is an important pre-requisite for more equitable educational practice and outcomes. .

\section{References}

Ainscow, M., Dyson, A., Goldrick, S. and West, M. (2012). Developing Equitable Education Systems. London: Routledge.

Ball, S. (1981). Beachside Comprehensive: a case-study of secondary schooling. Cambridge: Cambridge University Press.

Ball, S., Bowe, R. \& Gewirtz, S. (1994). Competitive Schooling: Values, Ethics and Cultural Engineering Journal of Curriculum and Supervision, 9, 350-367.

Ball, S. (2013). The Education Debate (second edition). Bristol: Policy Press.

Boaler, J. (1997). Setting, Social Class and Survival of the Quickest, British Educational Research Journal, 23, 575-595.

Boaler, J., Wiliam, D. \& Brown, M. (2000). Students' Experiences of Ability Grouping-disaffection, polarisation and the construction of failure, British Educational Research Journal, 26, 631-648.

Cassen, R. and Kingdon, G (2007). Tackling low educational achievement. York: Joseph Rowntree Foundation.

Clifton, J. \& Cook, W. (2012). A Long Division: Closing the attainment gap in England's secondary schools. London: IPPR.

CMPO (2004). Selective Education: Who Benefits from Grammar Schools? CMPO Bulletin Issue 11. Bristol: University of Bristol. 
Cook, C. (2012). The social mobility challenge for school reformers. $22^{\text {nd }}$ February 2012. URL:

http://blogs.ft.com/ftdata/2012/02/22/social-mobility-and-schools/\#axzz1n6Xg9ZMT. Retrieved $9^{\text {th }}$ August 2012.

Cook, C. (2013). Floor targets and social mobility, http://blogs.ft.com/ftdata/2013/01/18/floor-targetsand-social-mobility/ Retrieved $12^{\text {th }}$ March 2015.

Crozier, G. \& Reay, D. (Eds) (2005). Activating Participation: mothers, fathers and teachers working towards partnership. Stoke-on-Trent: Trentham Books.

Crozier, G. Reay, D. James, D. (2011). Making It Work for Them: White Middle Class Families and Working Class Schools. International Studies in Sociology of Education. 21, 199-216.

DfES (1997). Excellence in Schools, Government White Paper. London: HMSO. 'Excellence in Schools'

DCSF (2005) Higher Standards, Better Schools for All, Government White Paper. London: The Stationary Office.

Dracup, T. (2014) The Politics of Setting, https://giftedphoenix.wordpress.com/2014/11/12/the-politicsof-setting/ Retrieved: $6^{\text {th }}$ March 2015.

Dunne, M., Hunphreys, J., Sebba, J., Dyson, A., Gallanmaugh, F. and Muijs, D. (2007). Effective teaching and learning for pupils in low attaining groups. London: DCSF.

Education Endowment Foundation Toolkit (2015) http://educationendowmentfoundation.org.uk/toolkit/ Retrieved: $12^{\text {th }}$ March 2015.

Exley, S. (2012). School choice - parental freedom to choose and educational equality. In: Park, A., Clery, E., Curtice, J., Phillips, M. and Utting, D (Eds.) British social attitudes 2011-2012. London: NatCen Social Research / Sage.

Edwards, R. \& Nicholl, K. (2006). Expertise, competence and reflection in the rhetoric of professional development, British Educational Research Journal, 32, 115-131.

Edwards. R., Nicholl, K., Solomon, N. \& Usher, R. (2004). Rhetoric and educational discourse: persuasive texts?. London: RoutledgeFalmer.

Fereday, J. \& Muir-Cochrane, E. (2006). Demonstrating Rigor Using Thematic Analysis: A hybrid approach of inductive and deductive coding and theme development. International Journal of Qualitative Methods, 5, 1-11.

Feyerabend, P. (1975) Against Method: Outline of an Anarchistic Theory of Knowledge. London: New Left Books.

Ford, J. (1969) Social Class and the Comprehensive School. London: Routledge \& Kegan Paul.

Foucault, M. (1980). Power/Knowledge: Selected interviews and other writings, 1972-1977. New York: Pantheon.

Francis, B. (2015) Impacting policy discourse? An analysis of discourses and rhetorical devices deployed in the case of the Academies Commission. Discourse: Studies in the cultural politics of education, 36, 437-451. 
Francis, B. \& Hutchings, M. (2013) Parent Power? London: The Sutton Trust.

Francis, B. \& Wong, B. (2013) What is preventing social mobility? Literature Review, Leicester: ASCL.

Hallam, S. and Ireson, J. (2005). Secondary School Teachers' pedagogic practices when teaching mixed and structured ability classes. Research Papers in Education, 20, 3-24

Hallam, S. and Ireson, J. (2007). Secondary school pupils' satisfaction with their ability grouping placements. British Educational Research Journal, 33, 27-45

Hallam, S. and Toutounji, I. (1996). What do we know about the grouping of pupils by ability? A Research Review. London: Institute of Education.

Hallam, S., Ireson, J., Lister, V., Andon Chaudhury, I. and Davies, J. (2003). Ability grouping in the primary school: a survey, Educational Studies, 29, 69-83.

Hammersley, M. (2008) Paradigm war revived? On the diagnosis of resistance to randomized controlled trials and systematic review in education, International Journal of Research \& Method in Education, 31, 310.

Harlen, W. and Malcolm, H. (1997). Setting and Streaming: A research review. Edinburgh: Scottish Council for Research in Education.

Husbands, C. (2012). Teaching talent: raising quality in education. Speech to Social Market Foundation, September 2012.

Hutchings, M., Francis, B. \& De Vries, R. (2014). Chain Effects: The impact of academy chains on lowincome students. London: The Sutton Trust.

Ireson, J. \& Hallam, S. (2001). Ability Grouping in Education. London: Paul Chapman Publishing.

Ireson, J., Hallam, S. and Hurley, C. (2005). What are the effects of ability grouping on GCSE attainment? British Educational Research Journal, 31, 313-328.

Jackson, B. (1964). Streaming: An Education system in miniature. London: Routledge \& Kegan Paul.

Jerrim, J. \& Macmillan, L. (2014). Income inequality, intergenerational mobility and the Great Gatsby Curve: is education the key? DoQSS working paper http://ideas.repec.org/s/qss/dqsswp.html Retrieved: 12th March 2015.

Kohn, A. (1998). Only for My Kid: How Privileged Parents Undermine School Reform, Phi Delta Kappan, http://www.alfiekohn.org/article/kid/ Retrieved: $6^{\text {th }}$ March 2015.

Kutnick, P., Sebba, J., Blatchford, P., Galton, M., Thorpe, J., with Maclntyre, H. \& Berdondini,L. (2005). The Effects of Pupil Grouping: Literature Review. Research Report 688: London: DfES.

Linchevski, L., and Kutscher, B. (1998). Tell me with whom you're learning and I'll tell you how much you've learned: mixed-ability versus same-ability grouping in mathematics. Journal for Research in Mathematics Education, 29, 533-54. 
Lupton, R. (2014). Raising Teachers' Voice on Achievement in Urban Schools in England: An Afterword, Urban Review, DOI 10.1007/s11256-014-0311-8

Lupton, R., N. Heath and Salter, E. (2009). Education: New Labour's top priority, in: J. Hills, T. Sefton and K. Stewart (Eds) Towards a more equal society? Poverty, inequality and policy since 1997. Bristol: Policy Press.

Lyotard, J. (1984). The Postmodern Condition. Manchester: Manchester University.

Macqueen, S. (2012). Academic outcomes from between-class achievement grouping: the Australian primary context. The Australian Educational Researcher, 39, 59-73. doi: 10.1007/s13384-011-0047-3

Nicholl, K. \& Edwards, R. (2004). Lifelong learning and the sultans of spin: policy as persuasion?, Journal of Education Policy, 19, 43-55.

Nomi, T. (2009). The Effects of Within-Class Ability Grouping on Academic Achievement in Early Elementary Years, Journal of Research on Educational Effectiveness, 3, 56-92.

OECD. (2014). Are grouping and selecting students for different schools related to students' motivation to learn? PISA in focus 39. Paris: OECD.

Oakes, J. \& Guiton, G. (1995). Matchmaking: The Dynamics of High School Tracking Decisions. American Educational Research Journal, 32, 3-33. doi: 10.3102/00028312032001003

Parker, I. (1990). Discourse: Definitions and contradictions, Philosophical Psychology, 3, 187-204.

Reay, D. (1998). Class Work: Mothers' involvement in children's schooling. London: University College Press.

Reay, D., Crozier, G. \& James, D. (2011). White Middle Class Identities and Urban Schooling. London: Palgrave Press.

Savage, M. (2015). 'Cameron backs setting by ability', The Times, 26.1.15, http://www.thetimes.co.uk/tto/news/politics/article4365866.ece Retrieved: 6th March 2015.

Schleicher, A. (2012). '4 C's': Creativity, Critical thinking, Communication, Collaboration. In: Teachers and Developing School Leaders for the 21st Century: Lessons from around the world, Paris: OECD.

Slavin, R. (1990). Achievement effects of ability grouping in secondary schools: a best evidence synthesis. Review of Educational Research, 60, 471-499.

Stobart, G. (2008). Testing Times: the uses and abuses of assessment. London: Routledge.

Stuart, W. (2013). 'Streaming is out - now you can go with the flow', TES, 19.4.13;

https://www.tes.co.uk/article.aspx?storycode=6329982 Retrieved: $12^{\text {th }}$ March 2015.

Tomlinson, S. (1987). Curriculum option choices in multi-ethnic schools in: B.Troyna (Ed.) Racial Inequality in Education. London, Tavistock.

Vincent, C. \& Ball, S. (2006). Childcare, Choice and Class Practices: Middle Class Parents and their Children. London: Routledge. 
Vincent, C. \& Ball, S. J. (2007). 'Making up' the middle class child: Families, activities and class dispositions. Sociology, 41, 1061-1077.

Warwick, I. (2013). How should schools respond to Ofsted's renewed focus on G\&T?. Optimus Education. http://www.optimus-education.com/how-should-schools-respond-ofsteds-renewed-focus-gt Retrieved: 12th March 2015.

Waldfogel, J. \& Washbrook, E. (2010). Low income and early cognitive development in the U.K. A Report for the Sutton Trust. London: The Sutton Trust.

White, J. (2005). Puritan intelligence: the ideological background to IQ. Oxford Review of Education, 31), 423-442.

Whitty G. and Anders, J. (2014). (How) did New Labour narrow the achievement and participation gap? Centre for Learning and Life Chances in Knowledge Economies and Societies.

Wintour, P. (2014). 'Compulsory setting: schools face being forced to separate pupils by ability'. The Guardian, 3.9.14. http://www.theguardian.com/politics/2014/sep/03/schools-separate-pupils-abilitysetting Retrieved: 9th March 2015.

\footnotetext{
' Or rather, as Lupton (2014) points out, schools' lack of readiness for these children.

ii It is worth noting that, within this very large body of literature, there remains some contestation, with the occasional study finding beneficial impacts of tracking on attainment (see, e.g. Collins \& Gan, 2013). However, the overall lack of significance -excepting negative significance for some low attainers - remains a clear finding, and one that has stood the test of time. See http://educationendowmentfoundation.org.uk/toolkit/ability-grouping/ iii The education policy advocacy does focus on setting, rather than streaming, for which it tends to be recognised there is scant educational rationale, let alone supportive research evidence. For example, Dracup (2014) cites a PQ response in 2009: "We do not promote streaming-where pupils are assigned to classes on the basis of an overall assessment of their general ability and pupils remain in their streamed classes across the majority of subjects - as it assumes that children will have the same level of ability in all subjects."

iv Debate around the validity of the possibility and/or extent of agency in taking up particular discourses continues (see e.g. the discussion between Jones, 1997 and Davies 1997). However, research shows how policymakers and members of the public can and do mobilise specific discursive narratives to ensure they are 'heard' by target audiences (Author, 2014).

${ }^{v}$ Albeit officially Ofsted remains neutral on grouping practice, see TES (2013).

vi And as one of our Reviewers points out, this historic legacy includes early (but still resonant) conceptions of IQ and 'ability': the long history of conception, research and application of IQ and ability testing go back to the end of the 19th century. Initial conceptualisations suggested that intelligence was inherited, and the controversial linking of such understandings to social class has persisted (see e.g. Ford, J. [1969] for discussion). Despite all the evidence suggesting that intelligence is malleable, these historic ideas and debates continue to underpin discourses that produce ability as fixed.
}

vii The British education system that included academic 'grammar schools', less academic (and more numerous) 'secondary moderns', and a few 'technical schools'; and wherein pupils were tested at 11 and allocated to schools accordingly. The system was largely replaced by comprehensives, but grammar schools remain in some English localities.

viii Notes from pilot schools meeting in Best Practice in Grouping Students Project, 18.11.14 and 21.1.15.

ix These are not the only discourses that support setting. A further narrative articulated by many teachers is that on the 'difficulty' of teaching mixed attainment groups, especially in certain disciplines such as maths. 
X Specifically, the project's aims are to:

1. Conduct an RCT to explore the effect size of an intervention on "best practice in setting by attainment" (which attempts to remediate poor practices associated with setting), on the attainment outcomes of young people.

2. Conduct a feasibility study and trial of an intervention on "best practice in mixed attainment grouping", in relation to young people's attainment outcomes.

3. Draw on findings concerning the relative progress and attainment of low achieving pupils experiencing the different interventions, to draw conclusions as to which approach is most effective at improving their progress and raising attainment.

4. Undertake mixed-method research to explore young people's experiences of different pupil grouping practices, and the impact of these on their social and educational identities.

5. Use findings to provide evidence on effective practices in pupil grouping, in relation to the socio-economic gap for attainment - and to impact practice accordingly.

Impact (or otherwise) of the project interventions will be tested against the control groups, with the eventual aim of being able to compare effect size across the two interventions to identify which practices are most effective in supporting pupils with low prior-attainment (along with the impact on other groups of students). We expect to report findings in 2018. 